\title{
Sikojen syöntikäyttäytyminen ja rehunkulutus ruokinta-asemalla
}

\author{
Kirsi Partanen ${ }^{1)}$, Jussi Peura ${ }^{2)}$, Matti Puonti ${ }^{3)}$ ja Päivi Volanto ${ }^{4)}$ \\ ${ }^{1)}$ MTT Kotieläintuotannon tutkimus, Tervamäentie 179, 05840 Hyvinkää, kirsi.partanen@mtt.fi \\ ${ }^{2)}$ Suomen Sianjalostus Oy, Mettisuontie 49, 35400 Längelmäki, jussi.peura@faba.fi \\ ${ }^{3)}$ Faba Jalostus, PL 40, 01301 Vantaa, matti.puonti@faba.fi \\ ${ }^{4)}$ Rehuraisio Oy, PL 101, 21201 Raisio, paivi.volanto@raisio.com
}

\section{Tiivistelmä}

Sianjalostuksen tarpeita varten on kehitetty tietokoneohjattuja ruokinta-asemia, joissa sikojen yksilöllisen rehunkulutuksen mittaaminen onnistuu helposti ja edullisesti suuressakin ryhmässä. Ruokintaasemat soveltuvat myös sikojen syöntikäyttäytymisen tutkimiseen. Tässä tutkimuksessa selvitettiin lihasikojen syöntikäyttäytymistä ja yksilöllistä rehunkulutusta ryhmäkasvatuksessa, kun siat saavat syödä rehua vapaasti ruokinta-asemasta. Lisäksi tutkimuksessa verrattiin ruokinta-asemasta ja kaukalosta ruokittujen sikojen rehunkulutusta ja kasvua sekä suositusten mukaisella 3-vaiheruokinnalla että uudella 2-vaiheruokinnalla, missä tavanomaista pidemmän alkukasvatuksen jälkeen sioille syötettiin yli 80-kiloisille sioille tarkoitettua loppukasvatusrehua.

Tutkimuksessa kasvatettiin yhteensä 200 lihasikaa Suomen Sianjalostus Oy:n Längelmäen keskuskoeasemalla. Siat olivat $16,4 \mathrm{~m}^{2}$ :n osaritiläkarsinoissa, 10 sikaa/karsina. Karsinoissa oli joko Schauerin ruokinta-asema tai kaukalo, ja molemmista siat saivat syödä rehua vapaasti. Sioilla oli joko ruokintasuositusten mukainen 3-vaiheruokinta (1-rehua 25 pv, 2-rehua 28 pv ja 3-rehua teurastukseen saakka) tai uusi 2-vaiheruokinta, jossa 1-rehua syötettiin $39 \mathrm{pv}$ ja sen jälkeen 3-rehua teurastukseen saakka. Ruokinta-asema rekisteröi jokaiselta käyntikerralta sian saapumis- ja lähtöajan ja punnitsi syödyn rehumäärän. Lisäksi Spotmix-rehunjakolaitteisto rekisteröi karsinakohtaisesti sioille vuorokauden aikana jaetun rehumäärän. Siat punnittiin kuudesti kokeen aikana ja ne teurastettiin 81-88 pv kasvatuksen jälkeen.

Siat oppivat käyttämään ruokinta-asemaa ensimmäisten kolmen koepäivän aikana. Yksilölliset erot käytön oppimisessa olivat kuitenkin suuria. Syöntikertojen lukumäärä per vrk suureni sikojen kasvaessa, mutta syöntikerrat lyhenivät. Siat käyttivät syömiseen sekä kokeen alussa että lopussa n. 60 min/vrk. Kasvatuksen keskivaiheilla syömiseen kului n. 70 min/vrk. Yhdellä syöntikerralla syöty rehumäärä ja syöntinopeus suurenivat sikojen kasvaessa.

Siat kävivät syömässä pääasiassa päiväaikaan. Aamupäivällä (klo 8-12) syöntikerrat olivat lyhyitä, alle 2 min pituisia, kun taas muina aikoina ne kestivät 2-3 min. Syöntikertojen pitenemisen myötä annokset suurenivat. Sikojen tunnissa syömä rehumäärä oli suurin klo 15-17 välillä. Vuorokauden aika ei vaikuttanut syöntinopeuteen. Ruokinta-asema oli käytössä keskimäärin 11 h/vrk ja käyttöaste oli suurimmillaan (jopa yli $50 \mathrm{~min} / \mathrm{h}$ ) iltapäivän tunteina. Alkukasvatuksessa aseman käyttöaste oli selvästi kaksihuippuinen: siat kävivät asemalla melko vilkkaasti aamulla 7-8 maissa ja erittäin vilkkaasti iltapäivän tunteina. Keskikasvatuksessa syönnin huippu oli edelleen iltapäivällä, mutta siat söivät melko vilkkaasti koko aamupäivän ajan. Keskikasvatuksessa asema oli käytössä lähes 12 h/vrk. Yösyömisen osuus pysyi melko samanlaisena koko kasvatuksen ajan.

Kolmivaiheruokinnassa rehun vaihtuminen 1-rehusta 2-rehuksi 5. ruokintaviikon alussa ei vaikuttanut sikojen rehunkulutukseen, mutta 2-vaiheruokinnassa siirtyminen 1-rehusta 3-rehuun 7. ruokintaviikon alussa hidasti syöntinopeutta ja pienensi rehun syöntiä parin viikon ajan. Koko kasvatusajan rehunkulutuksessa ja sikojen kasvussa ei ollut merkitseviä eroja 2- ja 3-vaiheruokinnan välillä, mutta 2-vaiheruokinnalla ruhon lihaprosentti oli hieman parempi. Siat söivät kaukalosta keskimäärin 15 \% enemmän rehua kuin ruokinta-asemasta, ja rehuhyötysuhdekin oli huonompi, mutta kasvunopeudessa ei ollut merkitsevää eroa. Hännänpurentaa oli vain ruokittaessa ruokinta-asemasta, ja se ilmeni pääasiassa kasvatuksen keskivaiheilla, kun aseman käyttöaste oli suurimmillaan.

Asiasanat: sika, syöntikäyttäytyminen, rehunkulutus, ruokintamenetelmä, vaiheruokinta 


\section{Johdanto}

Sianjalostuksen tarpeita varten on kehitetty tietokoneohjattuja ruokinta-asemia, joissa sikojen yksilöllisen rehunkulutuksen mittaaminen onnistuu helposti ja edullisesti suuressakin ryhmässä. Ruokintaasema tunnistaa syömään tulevan sian korvassa olevan transponderin avulla, ja päästää vain yhden sian kerrallaan syömään. Asema rekisteröi sian saapumis- ja lähtöajan ja punnitsee syödyn rehumäärän. Nämä tiedot tallentuvat tietokoneelle joka kerta, kun sika käy ruokinta-asemalla, ja niistä saadaan laskettua sian yksilöllinen rehunkulutus kasvatuksen aikana. Ruokinta-asemia voidaan hyödyntää myös sikojen syöntikäyttäytymisen tutkimisessa (Hyun et al. 1997, 1998, Hyun ja Ellis 2001, 2002). Tässä raportoidun lihasikojen kasvatuskokeen tavoitteena oli tutkia lihasikojen syöntikäyttäytymistä ja yksilöllistä rehunkulutusta ryhmäkasvatuksessa, kun siat saavat syödä rehua vapaasti ruokintaasemasta, ja verrata sikojen vapaata rehunkulutusta ja kasvua ruokittaessa ruokinta-asemasta tai kaukalosta. Tutkimuksessa selvitettiin myös miten erilaiset vaiheruokinnat vaikuttavat sikojen syöntikäyttäytymiseen, rehunkulutukseen ja kasvuun.

\section{Aineisto ja menetelmät}

Tutkimus tehtiin Suomen Sianjalostus Oy:n Längelmäen keskuskoeasemalla. Kokeeseen jaettiin 16 kymmenen lihasian karsinaa, jotka sijaisivat neljässä eri osastossa. Kokeen alkupuolella yhdessä osastossa tapahtuneen rehunvaihtovirheen vuoksi kokeeseen jaettiin lisää neljä 10 sian karsinaa, jotka sijaitsivat kahdessa eri osastossa. Yhteensä kokeessa oli 200 lihasikaa, joista 43 oli maatiaissikoja, 50 yorkshiresikoja ja 107 em. rotujen risteytyksiä. Sioista 20 \% oli emakoita ja 80 \% leikkoja.

Siat kasvatettiin 16,4 $\mathrm{m}^{2}$ :n osaritiläkarsinoissa, joissa oli joko ruokinta-asema tai $3 \mathrm{~m}$ pitkä kaukalo (Schauer Machinenfabrik, Itävalta). Ruokinta-asema sijaitsi karsinan etuosan ritiläalueella. Juomanippa ja -kuppi sijaitsivat myös ritiläalueella, mutta karsinan vastakkaisella laidalla ruokintaasemaan nähden. Ruokinta-asemassa oli rehua tarjolla vapaasti 24 h vuorokaudessa, mutta vain yksi sika pääsi syömään kerrallaan. Ruokinta-kaukalo oli kiinnitetty karsinoiden väliseinään. Kaukaloiden anturit tarkistivat kaukalossa olevan rehumäärän 30 min välein klo 6.00-8.30 ja klo 12.00-14.30 ja 60 min välein klo 16.00-22.00. Jos kaukalo oli syöty lähes tyhjäksi, Spotmix-rehunjakolaitteisto annosteli sinne lisää rehua. Muina aikoina rehua ei jaettu. Laitteisto jakoi kaukaloon kerralla 40 \% ko. ruokintaviikolle ohjelmoidusta päiväannoksesta (ruokintakäyrä oli 1,4-3,6 ry/sika/pv), mutta kuitenkin korkeintaan $10 \mathrm{~kg} /$ kerta. Käytännössä rehun saanti oli kaukaloruokinnallakin vapaata. Laitteisto lisäsi kaukaloon annostelun ajan myös vettä. Karsinassa oli myös vesinippa.

Puolessa karsinoista oli ruokintasuositusten mukainen 3-vaiheruokinta (1-rehua 25 pv, 2rehua 28 pv ja sen jälkeen 3-rehua teurastukseen saakka) ja lopuissa uusi 2-vaiheruokinta, jossa 1rehua syötettiin tavanomaista pitempään eli 39 pv ja sen jälkeen 3-rehua teurastukseen saakka. Tutkimusta varten suunniteltujen koerehujen ry-arvot olivat: 1-rehu 1,00, 2-rehu 0,99 ja 3-rehu 0,97 ry/kg, ja niissä oli sulavaa lysiiniä 9,5, 7,1 ja 6,1 g/ry. Siat teurastettiin 81-88 pv kasvatuksen jälkeen.

Ruokinta-asema rekisteröi jokaiselta käyntikerralta sian saapumis- ja lähtöajan ja punnitsi syödyn rehumäärä. Spotmix-rehunjakolaitteisto rekisteröi kuhunkin ruokinta-asemaan ja kaukaloon vuorokauden aikana jaetun rehumäärän, josta laskettiin karsinakohtainen rehunkulutus per sika ruokintamenetelmien vertailua varten. Siat punnittiin kokeen alussa, 25., 39., 53. ja 74. koepäivänä ja teuraaksi lähtiessä. Ruhon lihaprosentti mitattiin Hennessy GP -mittarilla.

Ruokinta-aseman keräämistä tiedoista laskettiin sikojen käynti- ja syöntikertojen lukumäärä, syömiseen käytetty aika ja syöty rehumäärä vuorokaudessa ja vuorokauden eri tunteina, syöntinopeus ja automaatin käyttöaste, ja päivittäisestä rehunkulutuksesta ruokintaviikon keskisyönti, ry/pv. Sikojen tuotantotulokset analysoitiin käyttäen mallia, jossa oli ruokintamenetelmän ja vaiheruokinnan kiinteät vaikutukset ja näiden yhdysvaikutus. Havaintoyksikkönä oli karsina.

\section{Tulokset ja tulosten tarkastelu}

Aineistosta poistettiin yhdestä osastosta kaksi 3-vaiheruokinnalla ollutta karsinaa (sekä kaukalo että ruokinta-asema) rehunvaihtovirheen vuoksi. Lisäksi saman osaston kahden karsinan (kaukalo ja ruokinta-asema 2-vaiheruokinnalta) kolmen viimeisen kasvatusviikon rehunkulutustiedot olivat kadonneet tietokoneelta. Ko. osaston karsinoiden tilalle jaettiin neljä uutta karsinaa, mutta näistä kahden sikoja ei ollut tätä kirjoitettaessa vielä teurastettu. Karsinoista, joissa oli ruokinta-asema, poistettiin kolme sikaa hännänpurennan, kaksi jalkavaivojen ja kaksi kasvun pysähtymisen vuoksi, ja kolme sikaa kuoli tai lopetettiin mahahaavan vuoksi ja kaksi kuoli suolikierteeseen. Kaukalokarsinoiden sioista 
kolme kuoli tai lopetettiin mahahaavan ja yksi poistettiin jalkavaivojen vuoksi. Kaukalokarsinoissa ei havaittu hännänpurentaa.

\section{Syöntikäyttäytyminen ruokinta-asemalla}

Siat kävivät ruokinta-asemalla 1. koevuorokauden aikana keskimäärin 25 kertaa (min. 1 ja maks. 69 krt/vrk), mutta 19,7 \%:ssa käynneistä sika ei ollut syönyt rehua. Näitä tyhjiä käyntejä oli 2. koepäivänä 8,4 \% ja 3. koepäivänä 6,6 \% kaikista käynneistä. Neljännestä koepäivästä alkaen tyhjien käyntien osuus pysyi 3-5 \% välillä. Tämän perusteella siat oppivat käyttämään ruokinta-asemaa muutamassa päivässä. Yksilölliset erot olivat kuitenkin suuria ja ensimmäisten kolmen koepäivän aikana tyhjien käyntien osuus vaihteli 0-65\% sikojen välillä.

Syöntikertojen lukumäärä per vrk suureni sikojen kasvaessa, mutta syöntikerrat lyhenivät (kuvio 1). Siat söivät sekä kokeen alussa että lopussa keskimäärin tunnin ajan vuorokaudessa. Kasvatuksen keskivaiheilla syömiseen kului n. 70 min/vrk. Yhdellä syöntikerralla syöty rehumäärä ja syöntinopeus suurenivat sikojen kasvaessa. Baumungin ym. (2006) tutkimuksessa syöntikertojen lukumäärä pysyi tasaisena 112 pv kestäneen kasvatuksen aikana, mutta syömiseen käytetty aika lyheni 70:stä 50-60 minuuttiin/vrk ja syöntinopeus suureni 20:stä 40-50 g:aan/min rodusta riippuen.

Syöntikertoja, kpl/vrk
Syöntiaika, min/vrk
Rehua, g/syöntikerta
Syöntinopeus, g/min

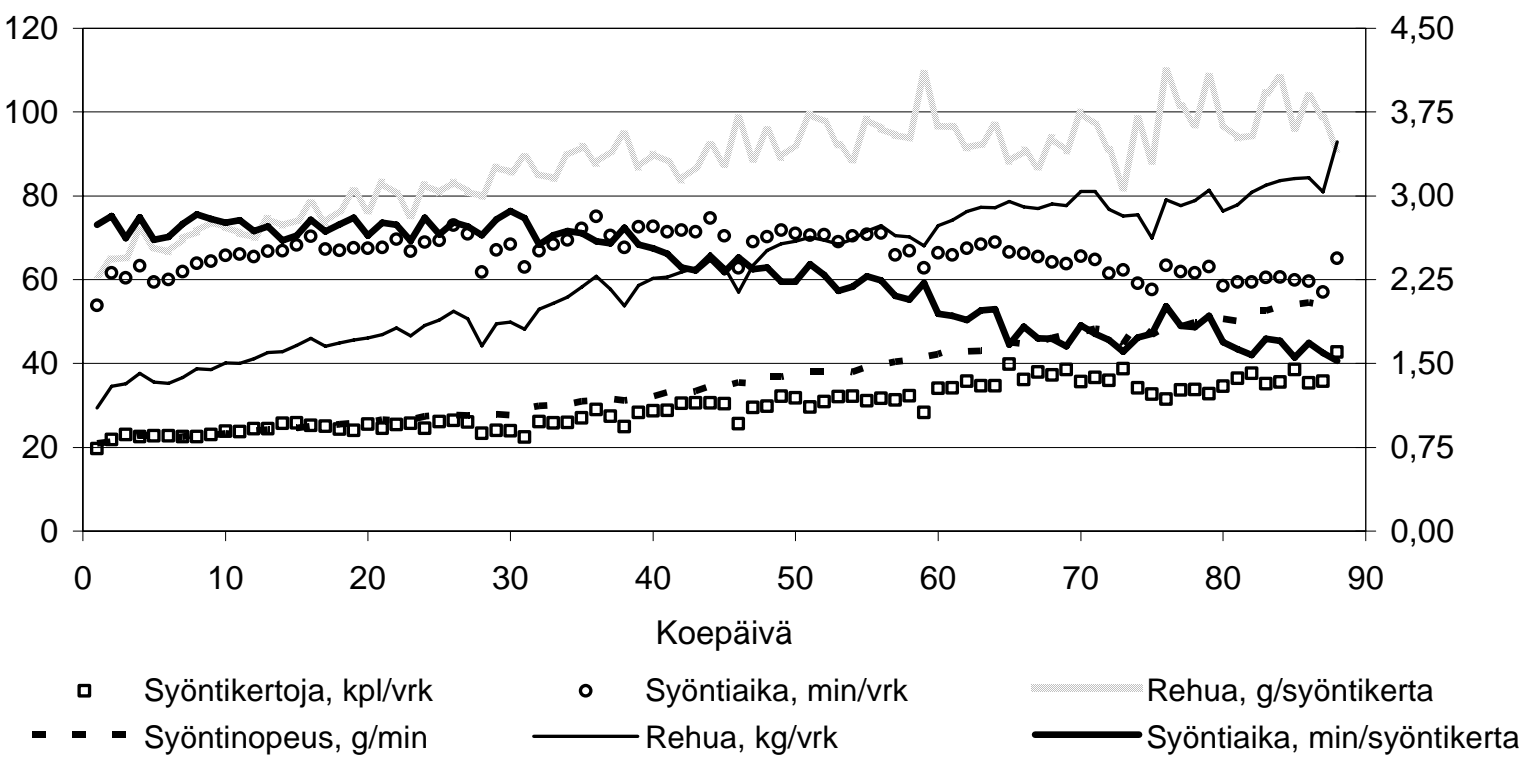

Kuvio 1. Sikojen syöntikäyttäytyminen ja rehunkulutus kasvatuksen aikana.

Siat kävivät syömässä pääasiassa päiväaikaan, klo 7-17 välillä, jolloin syöntikertoja oli keskimäärin 3 kpl/h syömässä käynyttä sikaa kohti. Aamupäivällä (klo 8-12) syöntikerrat olivat lyhyitä, alle 2 min pituisia, kun taas muina aikoina ne kestivät 2-3 min (kuvio 2). Syöntikertojen pitenemisen myötä annokset suurenivat. Tunnin aikana syömässä käyneiden sikojen syömä rehumäärä oli suurin klo 15-17 välillä. Baumungin ym. (2006) tutkimuksessa (10-13 sikaa per karsina) siat kävivät syömässä pääasiassa klo 6-20 välillä ja syönnin huippu oli sekä syöntikertojen lukumäärän, asemalla käytetyn ajan että syödyn rehumäärän perusteella klo 13-17 välillä. Hyunin ja Ellisin $(2001,2002)$ tutkimuksissa sikojen syöntihuippu oli aamulla klo 8 maissa. Sikalan valaistus, sikalassa tehtävät toimenpiteet ja lämpötila ovat tekijöitä, jotka todennäköisesti vaikuttavat myös sikojen aktiivisuuteen ja syömässä käymiseen. Sekä tässä että aikaisemmissa tutkimuksissa (Hyun ja Ellis 2001, 2002, Baumung 2006) vuorokauden aika ei vaikuttanut sikojen syöntinopeuteen. 


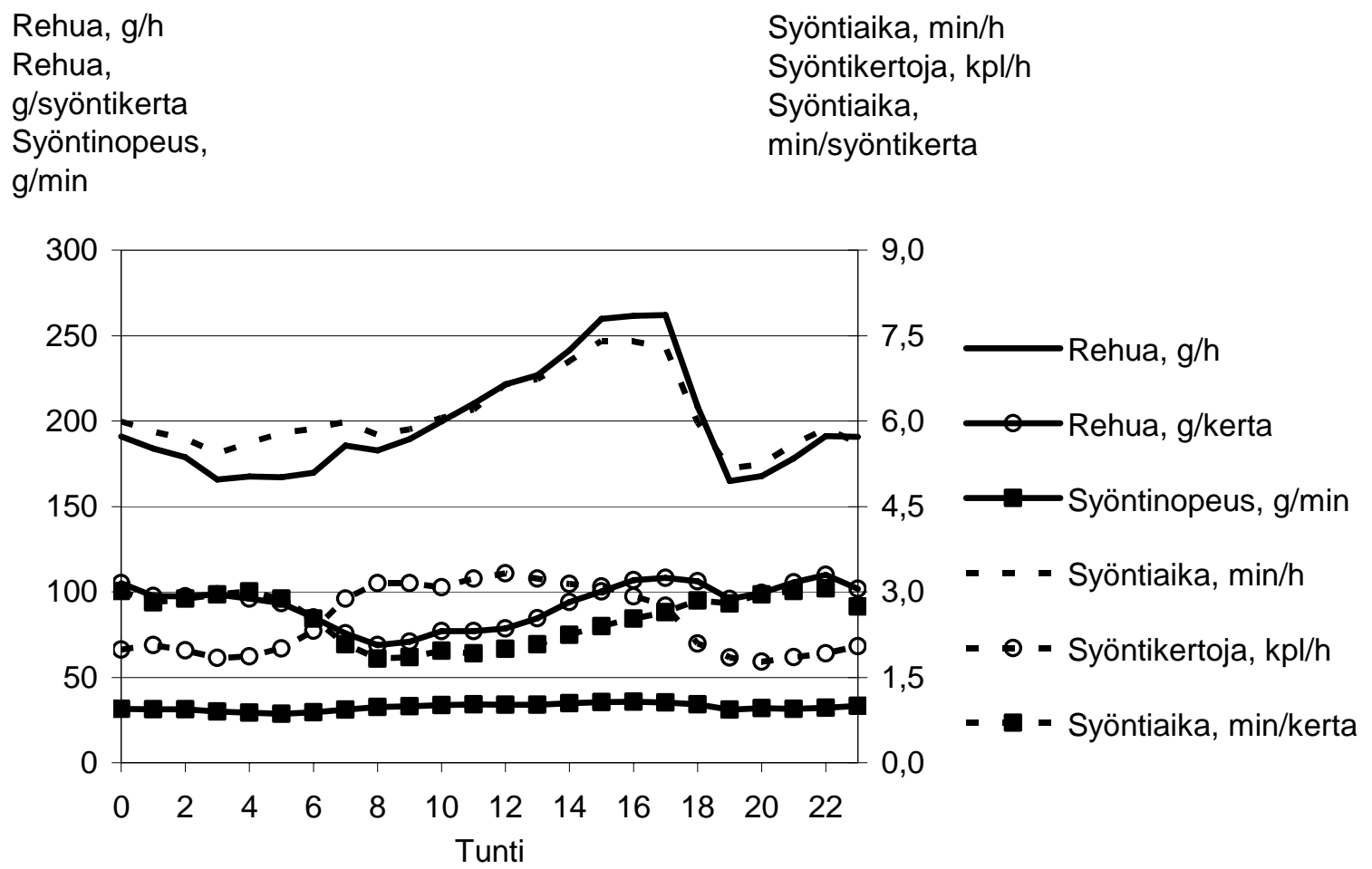

Kuvio 2. Sikojen syöntikäyttäytymistä kuvaavat tunnusluvut vuorokauden eri aikoina.

Karsinan kaikkien sikojen asemalla käyttämä aika oli keskimäärin 11 h/vrk. Aseman käyttöaste oli suurimmillaan iltapäivän tunteina, jolloin automaatti oli varattuna jopa yli $50 \mathrm{~min} / \mathrm{h}$ (kuvio 3). Alkukasvatuksessa aseman käyttöaika oli kaksihuippuinen eli siat kävivät asemalla melko vilkkaasti aamulla 7-8 maissa ja erittäin vilkkaasti iltapäivän tunteina. Kasvatuksen keskivaiheilla, 6.-8. koeviikolla syönnin huippu oli edelleen iltapäivällä, mutta aseman käyttö oli melko vilkasta koko aamupäivän ajan. Kasvatuksen keskivaiheilla asema oli käytössä lähes 12 h/vrk. Yöllä syömiseen käytetty aika ja syöntikertojen osuus vuorokauden syöntikerroista pysyi melko samanlaisena koko kasvatuksen ajan.



Kuvio 3. Ruokinta-aseman käyttöaika vuorokauden eri tunteina kasvatuksen aikana. 
Hännänpurentaa esiintyi vain karsinoissa, joissa siat saivat rehunsa ruokinta-asemasta. Ongelma tuli esiin kasvatuksen keskivaiheilla, jolloin aseman käyttöastekin oli suurimmillaan. Hännänpurennan esiintymiseen on voinut vaikuttaa myös heinäkuun alussa rehunjakolaitteistossa ollut toimintahäiriö, jolloin sikalan rehunjakelu katkesi.

\section{Vaiheruokintojenvertailu}

Rehun vaihtuminen 3-vaiheruokinnassa 1-rehusta 2-rehuksi 5. ruokintaviikon alussa ei vaikuttanut sikojen rehunkulutukseen verrattuna 1-rehun syöttämiseen. Sen sijaan 2-vaiheruokinnassa siirtyminen 1-rehusta 3-rehuun 7. ruokintaviikon alussa pienensi sikojen rehun syöntiä parin viikon ajan verrattuna 2-rehun syöttämiseen (kuvio 4). Vaikutus oli suurempi ruokittaessa ruokinta-asemasta kuin kaukalosta. Asemasta ruokittujen sikojen syöntinopeus hidastui siirryttäessä 1-rehusta täyttävämpään 3-rehuun. Sen sijaan syöntikertojen lukumäärässä ja pituudessa ja syöntiajassa ei tapahtunut yhtä selvää muutosta. Kasvatuksen keskivaiheilla automaatin käyttöaste oli suurimmillaan, eivätkä siat todennäköisesti pystyneet lisäämään täyttävämmän rehun syöntikertoja ja/tai syöntiaikaa kompensoidakseen rehun pienempiä energia- ja ravintoainepitoisuuksia. Loppukasvatusrehun matala aminohappopitoisuus on myös voinut vaikuttaa syöntiin. Hyunin ym. (1997) tutkimuksessa rehun lysiinipitoisuuden kasvaessa syöntikertojen määrä ja syöntinopeus eivät muuttuneet, mutta syöntikerrat ja syömiseen käytetty aika pitenivät ja käyntikerralla syöty rehumäärä suureni, mikä lisäsi päivässä syödyn rehun määrää. Tarkasteltaessa koko kasvatusaikaa, 2- ja 3-vaiheruokinnan väliset erot rehun päiväsyönnissä (+0,08 kg/pv), kokonaiskulutuksessa (-7 kg/sika), kasvunopeudessa (+40 g/pv) ja rehuhyötysuhteessa (-0,04 ry/kg) eivät olleet merkitseviä. Ruhon lihaprosentti oli kuitenkin hieman parempi 2-vaiheruokinnalla olleilla sioilla (taulukko 1).

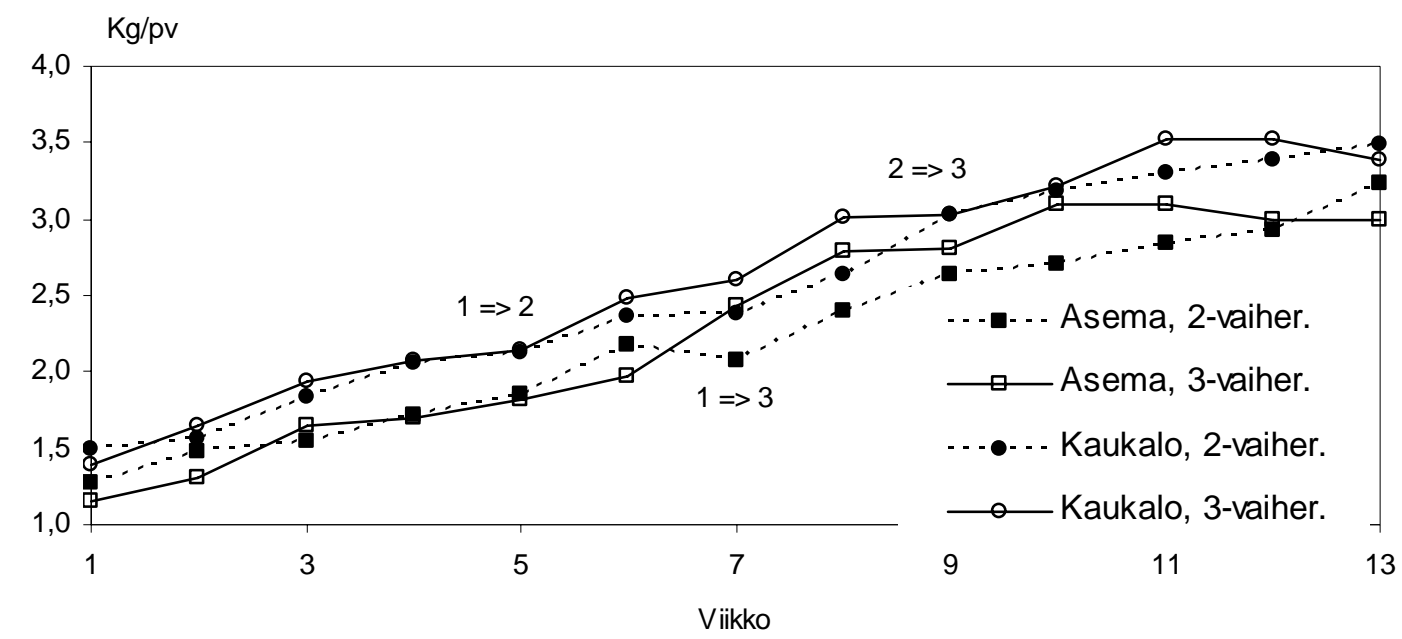

Kuvio 4. Sikojen rehunkulutus (kg/sika/pv) ruokinta-asemalla ja kaukalosta 2- ja 3-vaiheruokinnalla. Rehu vaihdettiin 2-vaiheruokinnalla 7. koeviikon alussa (1-rehusta 3-rehuun) ja 3-vaiheruokinnalla 5. (1-rehusta 2-rehuun) ja 9. koeviikon alussa (2-rehusta 3-rehuun).

\section{Ruokintamenetelmien ja vertailu}

Siat söivät koko kokeen ajan kaukalosta enemmän rehua kuin ruokinta-asemalta (kuvio 4). Ruokintamenetelmien välinen ero rehunkulutuksessa oli keskimäärin 15 \%. Sikojen päiväkasvussa ei ollut ruokintamenetelmien välillä merkitsevää eroa, mutta rehuhyötysuhde oli parempi ruokittaessa ruokintaasemasta kuin kaukalosta (taulukko 1). Kaukaloon annosteltuun rehuun lisättiin vettä, mutta asemasta siat söivät rehun kuivana. Rehun kostuttaminen voi olla yksi syy kaukalokarsinoiden suurempaan rehunkulutukseen. Toisaalta kaukaloruokinnan suurempi rehuhyötysuhde voi osittain johtua rehun helpommasta tuhlaantumisesta ruokinta-asemaan verrattuna. Ruokinta-asemasta ruokittujen sikojen pienempi rehunkulutus ja samoissa karsinoissa havaitut hännänpurentatapaukset viittaavat kuitenkin siihen, että ruokinta-aseman kapasiteetti ei ehkä ole riittävä 10 sian ruokkimiseen yhdestä asemasta. Ruokintamenetelmä ei vaikuttanut ruhon lihakkuuteen.

Siat yksilöllisesti tunnistavia ruokinta-asemia on tutkittu aikaisemmin, mutta vertailut kaukaloruokintaan ovat vähäisiä. Hyun ja Ellisin (2002) tutkimuksessa lihasikojen rehunkulutus oli 85-114 
kg painovälillä pienempi siat yksilöllisesti tunnistavalla ruokinta-asemalla kuin perinteisessä yhden ruokintapaikan ruokinta-asemassa, mutta sikojen kasvussa ei ollut merkitsevää eroa. Tutkimuksen siat pystyivät muuttamaan syöntikäyttäytymistään siten, että rehunkulutus ja kasvu eivät muuttuneet, kun sikojen lukumäärää per ruokinta-asema lisättiin kahdesta 12:een. Nielsenin ym. (1995) mukaan sikojen lukumäärän lisääminen viidestä 20:een per ruokinta-asema vähensi syöntikertojen lukumäärää, mutta pidensi niiden kestoa ja suurensi syöntinopeutta ja käyntikerralla syötyä rehumäärää vaikuttamatta kuitenkaan rehun kokonaiskulutukseen tai kasvuun. Sikojen syöntikäyttäytyminen on erilaista yhden ja useamman ruokailupaikan ruokintamenetelmissä, vaikka tuotantotuloksissa ei olekaan olennaista eroa (Nielsen ym. 1996). Georgsonin ja Svedsenin (2002) mukaan kilpailua aiheuttavat ruokintamenetelmät (ruokailupaikkojen määrä on pieni tai ruokintaa on rajoitettu) voivat huonontaa yksittäisten sikojen hyvinvointia, vaikka keskimääräiset tuotantotulokset pysyisivät hyvinä. Tässä tutkimuksessa hännänpurentaa oli vain ruokittaessa ruokinta-asemasta, ja se ilmeni pääasiassa kasvatuksen keskivaiheilla, kun aseman käyttöaste oli suurimmillaan. Vapaasta ruokinnasta huolimatta ruokintaasema näyttäisi johtavan kaukaloruokintaa herkemmin sikojen häiriökäyttäytymiseen. Sikojen poistojakin oli enemmän ruokittaessa ruokinta-asemasta.

Taulukko 1. Sikojen tuotantotulokset 2- ja 3-vaiheruokinnalla ruokittaessa ruokinta-asemasta tai kaukalosta.

\begin{tabular}{|c|c|c|c|c|c|c|c|c|}
\hline \multirow{2}{*}{$\begin{array}{l}\text { Ruokintamenetelmä } \\
\text { Ruokintavaiheita }\end{array}$} & \multicolumn{2}{|c|}{ Ruokinta-asema } & \multicolumn{2}{|c|}{ Kaukalo } & \multirow[b]{2}{*}{ SEM } & \multicolumn{3}{|c|}{ Tilast. merkitsevyys } \\
\hline & 2 & 3 & 2 & 3 & & $\mathrm{M}$ & $\bar{V}$ & $\mathrm{M} \times \mathrm{V}$ \\
\hline Alkupaino, kg & 32,5 & 33,2 & 32,1 & 33,3 & 0,9 & & & \\
\hline Loppupaino, kg & 108,4 & 112,2 & 114,0 & 115,4 & 3,4 & & & \\
\hline Rehua, kg/pv & 2,26 & 2,34 & 2,57 & 2,66 & 0,14 & $*$ & & \\
\hline Rehua, kg/sika & 197 & 204 & 224 & 232 & 12 & $*$ & & \\
\hline Kasvu, g/pv & 878 & 920 & 935 & 974 & 37 & & & \\
\hline Rehua, ry/kg & 2,53 & 2,50 & 2,71 & 2,67 & 0,07 & $*$ & & \\
\hline Lihaprosentti & 59,3 & 58,6 & 59,2 & 58,0 & 0,5 & & 0 & \\
\hline
\end{tabular}

\section{Johtopäätökset}

Tulosten perusteella siat syövät ruokinta-asemalla pääasiassa päiväaikaan, ja syönnin ruuhkahuippu on iltapäivällä. Sian syöntikäyttäytyminen muuttuu kasvatuksen aikana siten, että syöntikertojen lukumäärä vuorokaudessa, syöntinopeus ja käyntikerralla syöty rehumäärä kasvavat, mutta syöntikerrat lyhenevät. Sika käyttää syömiseen 60-70 minuuttia vuorokaudessa. Syömiseen käytetty aika oli pisin kasvatuksen keskivaiheilla. Uusi 2-vaiheruokinta, jossa 1-rehu vaihdettiin yli 80-kiloisille sioille tarkoitettuun 3-rehuun noin 65 kg painossa, pienensi sikojen rehunkulutusta parin viikon ajan rehunvaihdon jälkeen suositusten mukaiseen 3-vaiheruokintaan verrattuna, mutta vaikutus koko kasvatusajan kasvuun ja rehuhyötysuhteeseen ei ollut merkitsevä. Sikojen vapaa rehun syönti oli pienempi ja rehuhyötysuhde huonompi ruokittaessa ruokinta-asemasta kuin kaukalosta. Ruokintamenetelmä ei vaikuttanut merkitsevästi sikojen päiväkasvuun. Hännänpurentaa esiintyi vain ruokittaessa ruokintaasemasta.

\section{Kirjallisuus}

Baumung, R., Lercher, G., Willam, A. \& Sölkner, J. 2006. Feed intake behaviour of different pig breeds during performance testing on station. Arch. Tierz. Dummerstorf 49: 77-88.

Georgsson, L. \& Svendsen, J. 2002. Degree of competition at feeding differentially affects behaviour and performance of group-housed growing-finishing pigs of different relative weights. J. Anim. Sci. 80: 376-383.

Hyun, Y. \& Ellis, M. 2001. Effect of group size and feeder type on growth performance and feeding patterns in growing pigs. J. Anim. Sci. 79: 803-810.

Hyun, Y. \& Ellis, M. 2002. Effect of group size and feeder type on growth performance and feeding patterns in finishing pigs. J. Anim. Sci. 80: 568-574.

Hyun, Y., Ellis, M. \& Johnson, R.W. 1998. Effects of feeder type, space allowance, and mixing on the growth performance and feed intake pattern of growing pigs. J. Anim. Sci. 76: 2771-2778.

Hyun, Y., Ellis, M., McKeith, F.K. \& Wilson, E.R. 1997. Feed intake pattern of group-housed growingfinishing pigs monitored using a computerized feed intake recording system. J. Anim. Sci. 75: 1443-1451.

Nielsen, B.L., Lawrence, A.B. \& Whittemore, C.T. 1995. Effect of group size on feeding behaviour, social behaviour, and performance of pigs using single-space feeders. Livest. Prod. Sci. 44: 73-85.

Nielsen, B.L., Lawrence, A.B. \& Whittemore, C.T. 1996. Feeding behaviour of growing pigs using single or multi-space feeders. Appl. Anim. Behav. Sci. 47: 235-246. 